\title{
A soybean MADS-box protein modulates floral organ numbers, petal identity and sterility
}

\author{
Fang Huang, Guangli Xu, Yingjun Chi, Haicui Liu, Qian Xue, Tuanjie Zhao, Junyi Gai and Deyue Yu*
}

\begin{abstract}
Background: The MADS-box transcription factors play fundamental roles in reproductive developmental control. Although the roles of many plant MADS-box proteins have been extensively studied, there are almost no functional studies of them in soybean, an important protein and oil crop in the world. In addition, the MADS-box protein orthologs may have species-specific functions. Controlling male fertility is an important goal in plant hybrid breeding but is difficult in some crops like soybean. The morphological structure of soybean flowers prevents the cross-pollination. Understanding the molecular mechanisms for floral development will aid in engineering new sterile materials that could be applied in hybrid breeding programs in soybean.

Result: Through microarray analysis, a flower-enriched gene in soybean was selected and designated as GMMADS28. GmMADS28 belongs to AGL9/SEP subfamily of MADS-box proteins, localized in nucleus and showed specific expression patterns in floral meristems as well as stamen and petal primordia. Expression of GmMADS28 in the stamens and petals of a soybean mutant NJS-10Hfs whose stamens are converted into petals was higher than in those of wild-type plants. Constitutive expression of GMMADS28 in tobacco promoted early flowering and converted stamens and sepals to petals. Interestingly, transgenic plants increased the numbers of sepal, petal and stamen from five to six and exhibited male sterility due to the shortened and curly filaments and the failure of pollen release from the anthers. The ectopic expression of GMMADS28 was found to be sufficient to activate expression of tobacco homologs of SOC1, LEAFY, AGL8/FUL, and DEF. In addition, we observed the interactions of GMMADS28 with soybean homologs of SOC1, AP1, and AGL8/FUL proteins.

Conclusion: In this study, we observed the roles of GMMADS28 in the regulation of floral organ number and petal identity. Compared to other plant AGL9/SEP proteins, GmMADS28 specifically regulates floral organ number, filament length and pollen release. The sterility caused by the ectopic expression of GmMADS28 offers a promising way to genetically produce new sterile material that could potentially be applied in the hybrid breeding of crops like soybean.
\end{abstract}

Keywords: Fertility, Floral organ number, Petal identity, Glycine max, MADS-box transcription factors

\section{Background}

Many transcription factors (TFs) that control floral development in model plants, such as Arabidopsis, have been identified and constitute a genetic "ABC model" for specifying four-whorl floral organs: sepals, petals, stamens, and carpels [1,2]. Most TFs in the "ABC model" are so-called MADS-box transcription factors, which play fundamental roles in floral developmental control [3-5]. The ABC model proposes three classes of genes, termed A, B, and

\footnotetext{
* Correspondence: dyyu@njau.edu.cn

National key laboratory of crop genetics and germplasm enhancement, National Center for Soybean Improvement, Nanjing Agricultural University, Nanjing 210095, China
}

\section{() Biomed Central}

C. A genes alone specify sepals, A and B genes together specify petals, and $\mathrm{B}$ gene expression in combination with a $\mathrm{C}$ gene specifies stamens. Carpel formation is dependent on $\mathrm{C}$ gene expression alone. In addition, the $\mathrm{ABCD}$ model was suggested when FLORAL BINDING PROTEIN 11 (FBP11), termed a D-class gene, was confirmed to determine the ovule [6]. Although $A B C$ genes are critical for floral organ identity, their expression levels are not sufficient to convert leaves into floral organs, indicating that other genes are required. Further studies in Arabidopsis have identified E genes (SEPALLATA1-4, previously named AGL2, AGL4, AGL9, and AGL3), which are required to specify the identity of all four whorls of the 
floral organs and floral meristem determinacy [7-11]. Accordingly, the ABCDE model was proposed [12-14].

The SEPALLATA (SEP) or SEP-like genes have been described necessary, albeit redundantly, for the normal development of petals, stamens, carpels, and sepals $[8,13,15]$. It has been proposed that the SEP proteins could constitute higher-order complexes with $\mathrm{A}, \mathrm{B}$, or $\mathrm{C}$ proteins $[8,13,15]$, and at least one SEP protein is present in more than half of the 106 multimeric complexes identified through a large-scale yeast three-hybrid screen [16]. SEP proteins are necessary for the formation of the transcription factor complexes that control ovule development [17]. A single sep mutant shows either a subtle or no phenotype, whereas the sep1/2/3/4 mutant displays indeterminate flowers composed of only leaf-like organs; even sepal development is dependent on SEP function [10]. Although SEP4 is involved redundantly with the other SEP genes in the development of all floral organs, the sep 1/2/ $3 / 4$ quadruple mutant exhibits the more extreme phenotype of the loss of floral meristem identity compared to the sep1/2/3 triple mutants [10]. Additionally, the SEP3 mutation alone leads to a partial transformation of the petals into sepals, suggesting that SEP3 plays more predominant role in floral organ development than other SEP proteins [10]. SEP3 strongly activates the expression of the A gene $A P 1, \mathrm{~B}$ gene $A P 3$, and $\mathrm{C}$ gene $A G$; these factors are the major protein interaction partners of SEP3, suggesting that SEP3 can activate the flower developmental program by enhancing the expression of its interaction partners [18]. The mutation of a rice SEP-like gene, OsMADS34/PAP2, altered inflorescence morphology and increased the number of primary branches but decreased the number of secondary branches [19,20]. Moreover, osmads34 mutant displayed a decreased spikelet number and had lemma/leaf-like elongated sterile lemmas. Similar to the sep1/2/3/4 mutants of Arabidopsis, knock-down of the four rice $S E P$-like genes led to homeotic transformation of all the floral organs, except the lemma, into leaf-like organs, suggesting the conservation of SEP-like genes in specifying floral determinacy and organ identity in both eudicots and monocots [21].

The phenotypes of transgenic plants constitutively expressing SEP genes have been analyzed to further study their functions. Pelaz et al. [22] found that the overproduction of SEP3 in Arabidopsis led to early flowering and that the secondary shoots were transformed into solitary flowers. Furthermore, the ectopic expression of SEP3 was found to be sufficient to activate other B and $\mathrm{C}$ genes, and the constitutive expression of SEP3 and $L E A F Y$, a floral meristem identity gene, produced ectopic petals, carpels, and ovules outside of the floral context [23]. Zhao et al. [24] found that the ectopic expression of a wheat SEP-like gene, TaMADS1, caused early flowering and altered the development of all floral organs, including sepals converted into leaf-like structures and decreases in the petal and stamen number. The overexpression of SEP3 genes from tobacco and rice in Arabidopsis or tobacco promotes early flowering but does not significantly affect floral morphology $[25,26]$.

Soybean (Glycine max [L.] Merr.) is an important global crop that provides protein and oil. Understanding of the processes that occur during soybean reproductive development and the identification of the genes responsible for developmental processes is important for soybean breeding. However, only a few reproductive-related genes have been identified in soybean, including GmAP1 [27], GmNMH7 [28], and GmGAL1 [29]. Additionally, none of these soybean MADS-box genes were shown to alter floral morphology. As an attempt to understand flower developmental process in soybean and genetically modify soybean floral morphology for breeding applications, we identified 28 flower-enriched transcription factors in soybean through a microarray analysis [30]. Here, we report the functions of GmMADS28 which plays pivotal roles in the regulation of floral organ number and petal identity. The sterility caused by the ectopic expression of GmMADS28 offers a promising approach to genetically produce new sterile material that could potentially be applied in crop hybrid breeding. Through the identification of more genes related with soybean flower, engineering soybean sterile materials applied in hybrid breeding programs will be possible.

\section{Results}

\section{GmMADS28 is a member of Class E MADS-box genes}

Among 28 transcription factor genes predominantly expressed in soybean flowers [30], a soybean homolog (Gma.17031.1.A1_at) of Arabidopsis AGL9/SEP3 was selected for further analysis in the present study. The microarray data were confirmed by real-time qPCR (Figure 1a). We named this gene GmMADS28 because it showed the highest similarity with Arabidopsis SEP3. First, we cloned the cDNA fragment of GmMADS28 via RTPCR from soybean flowers. Through RACE-PCR, we assembled and cloned the full-length cDNA of GmMADS28, which is 1,026 bp in length and contains an ORF of $732 \mathrm{bp}$. The sequence of GmMADS28 has been deposited in GenBank/EMBL under accession number AJ878424.

Comparison of the GmMADS28 cDNA and soybean genomic DNA sequences suggested that GmMADS28 contains eight exons and seven introns. By comparison of the exon-intron structures of GmMADS28 and other plant MADS-box genes, we found that GmMADS28 and other plant SEP genes share the same numbers of exons and introns; each exon size is highly conserved, whereas the intron size is divergent (Figure 1b). The maize $A G$ gene $Z A G 2$ has seven exons, though the sizes of the first six exons covering the MADS- and K-domains are similar 


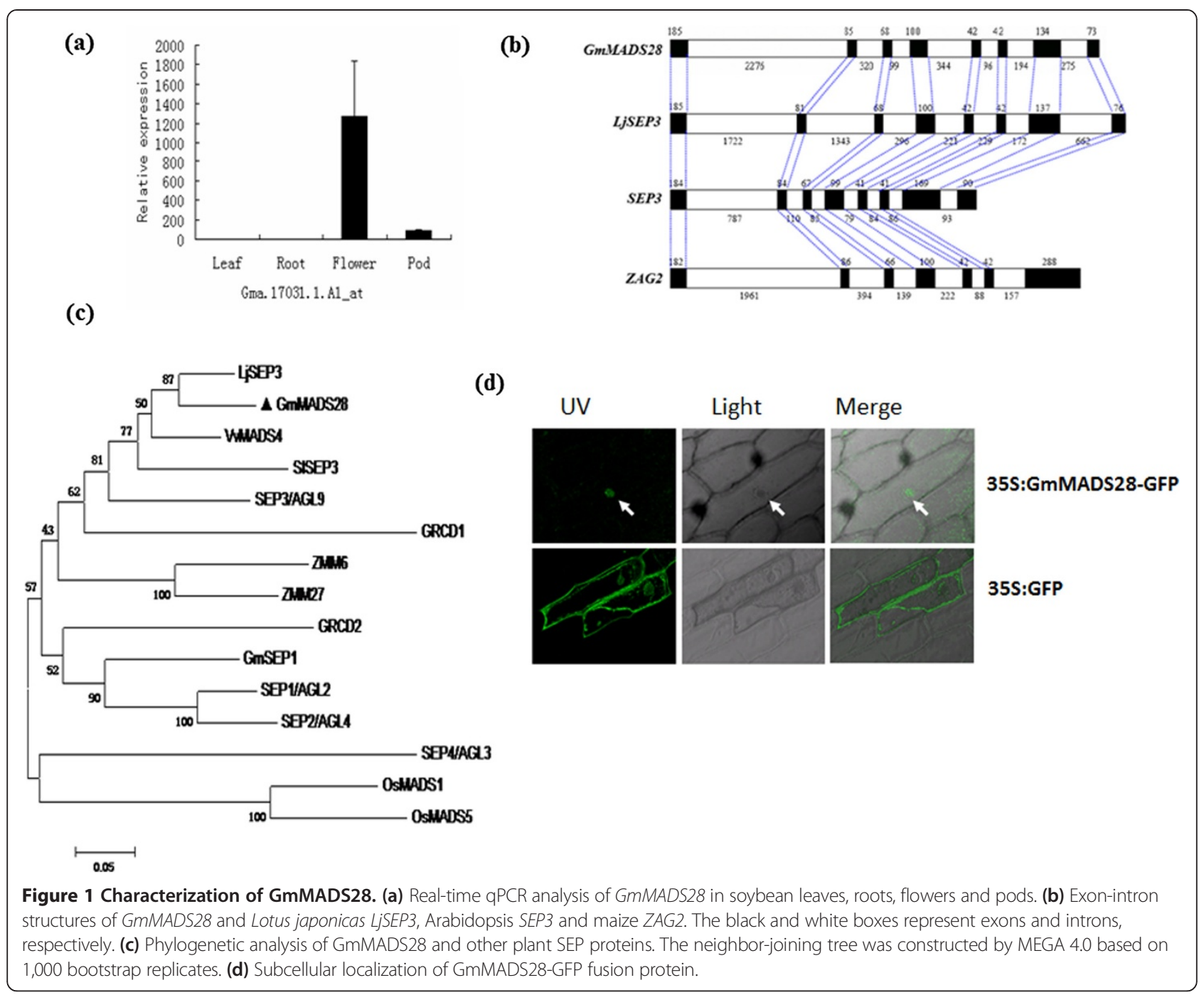

to those of GmMADS28. These results suggested that sequence alteration in the MADS-box genes during genome duplications, particularly in the $3^{\prime}$ region, might have resulted in divergent subfamilies of plant MADS-box proteins.

The deduced GmMADS28 protein contains 243 amino acids and has a molecular mass of $27.9 \mathrm{kDa}$. Database searches suggested that GmMADS28 is homologous to Arabidopsis SEP3 (identity of $74 \%$ and similarity of $83 \%$ ), SEP1 (identity of $59 \%$ and similarity of $71 \%$ ), SEP2 (identity of $60 \%$ and similarity of $71 \%$ ), and SEP4 (identity of $47 \%$, and similarity of $64 \%$ ). The alignment of GmMADS28 and the other plant MADS-box proteins showed that the amino acid sequences in the MADS domains were highly conserved. In addition to the MADS domain, the intergenic region (I region), K-box, and a $\mathrm{C}$-terminal region ( $\mathrm{C}$ region) are included in each MADS-box protein. Moreover, a potential phosphorylation site, RQVTF, for calmodulin-dependent protein kinases and three common sequences, the "SEP motif I", "SEP/AGL6 motif", and "SEP motif II" [31,32], were found in all the analyzed SEP proteins, including GmMADS28.

To address relationship of GmMADS28 to other plant SEP proteins, a neighbor-joining phylogenetic tree was constructed based on the alignment of amino acid sequences from the plant SEP proteins (Figure 1c). The tree showed that GmMADS28 was grouped into the plant SEP3 subfamily. In particular, GmMADS28 was closer to Lotus japonicas LjSEP3 and Arabidopsis SEP3. These results suggest that GmMADS28 is an E gene; based on the tree and highest sequence identity between GmMADS28 and SEP3.

\section{GmMADS28 is localized in the nucleus}

To assess the subcellular localization of GmMADS28, we fused the full-length ORF of GmMADS28 to the green fluorescence protein (GFP) reporter gene under the control of the CaMV35S promoter to generate the construct 
35S:GmMADS28-GFP. The construct and the empty vector were transformed into onion epidermal cells via Agrobacterium-mediated transformation. Confocal imaging of GFP fluorescence showed that the GmMADS28GFP fusion protein was localized to the nucleus; in contrast, the GFP fluorescence was distributed throughout the cells when the cells were transformed with GFP alone (Figure 1d).

\section{Transcripts of GmMADS28 accumulate predominantly in reproductive organs, especially in petals}

The expression profiles of the GmMADS28 in various soybean tissues were investigated by semi-quantitative RTPCR. Various soybean tissues, including leaf, flower, root, shoot apex, seed, stem, and pod, were collected. The expression analysis showed that the GmMADS28 mRNA was clearly detected in the reproductive organs, including the flower, seed, and pod, but not in the leaf or root (Figure 2). Weak expression of GmMADS28 in the vegetative shoot apex was also found (Figure 2). To further analyze the expression of GmMADS28 in flowers, we examined the expression of GmMADS28 in the four whorl organs: sepal, petal, stamen, and carpel. As shown in Figure 2, GmMADS28 was clearly detected in all four organs and showed the highest expression in petals.

Because GmMADS28 was highly expressed in developing seeds (Figure 2), it is of interest to investigate whether GmMADS28 is involved in soybean seed development. Thus, we performed a semi-quantitative RT-PCR assay to analyze the time-course expression pattern of GmMADS28 during soybean seed development. The results showed that $G m M A D S 28$ was highly expressed at 15 and 20 DAF (days after flowering) but was downregulated thereafter, with the lowest level at $35 \mathrm{DAF}$; the expression of GmMADS28 increased gradually after 40 DAF (Additional file 1: Figure S1). These results suggested that GmMADS28 may play some roles at the early and late stages of seed development.

\section{In situ localization of GmMADS28 transcript}

To further analyze the spatial distribution of GmMADS28, mRNA in situ hybridization was employed to detect floral
mRNA expression. In the early stages of flower development, transcripts of GmMADS28 were localized in the floral meristem (Figure $3 \mathrm{~b}$ ), and in the stamen and petal primordia (Figure $3 \mathrm{c}-\mathrm{d}$ ). In the late stages of flower development, transcripts of $G m M A D S 28$ were detected in the stamens, petals, and ovules (Figure 3e-f).

\section{GmMADS28 promotes early flowering}

To analyze the biological role of GmMADS28, we ectopically expressed the GmMADS28 gene in tobacco (Figure 4a) and obtained 13 independent transgenic lines overexpressing GmMADS28 confirmed by RT-PCR analysis (Additional file 2: Figure S2). We found that all positive 35S:GmMADS28 plants flowered significantly earlier than the wild-type plants. As the plants have a fixed number of leaves when flowering under the same environment, a comparison of the flowering time was evaluated by the leaf number. The 35S:GmMADS28 plants produced an average of only 22 leaves when flowering, whereas the wild-type plants produced approximately 34 leaves (Figure 4b). The 35S:GmMADS28 plants also exhibited reduced plant height compared to the wild-type plants (Figure 4c).

\section{Ectopic expression of GmMADS28 affects morphology of floral organs}

The GmMADS28 over-expression lines exhibited remarkable morphological alterations in the floral organs. In wild-type plants, the number of petals, stamens, and sepals is five, but six 35S:GmMADS28 lines displayed six for each organ (Figure $5 \mathrm{a}-\mathrm{c}, \mathrm{e}-\mathrm{h}$ ). Interestingly, antisense expression of GmMADS28 in transgenic tobacco reduces the numbers of petals from five to four but the numbers of other three whorl organs are still five (Figure $5 \mathrm{~d}$ ). Besides, four 35S:GmMADS28 lines converted the stamens into petals and two converted the sepals into petals. The ectopic expression of GmMADS28 could convert the sepals and stamens into petals (Figure $5 \mathrm{i}, \mathrm{j}$ ), implying the regulation by GmMADS28 in petal identity.

Moreover, the sepals of the three 35S:GmMADS28 transgenic lines were more similar to the carpels than to the sepals of the wild-type plant (Figure 6a-c). The inner and

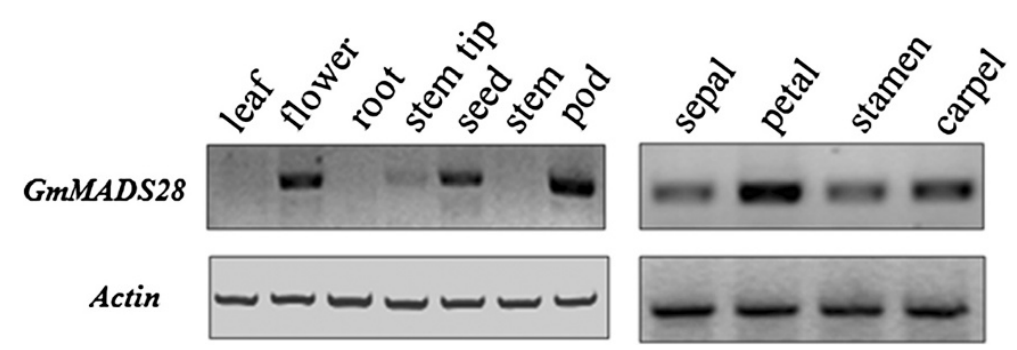

Figure 2 GmMADS28 expression in different tissues of soybean by semi-quantitative RT-PCR analysis. Actin gene was used as the reference gene. 

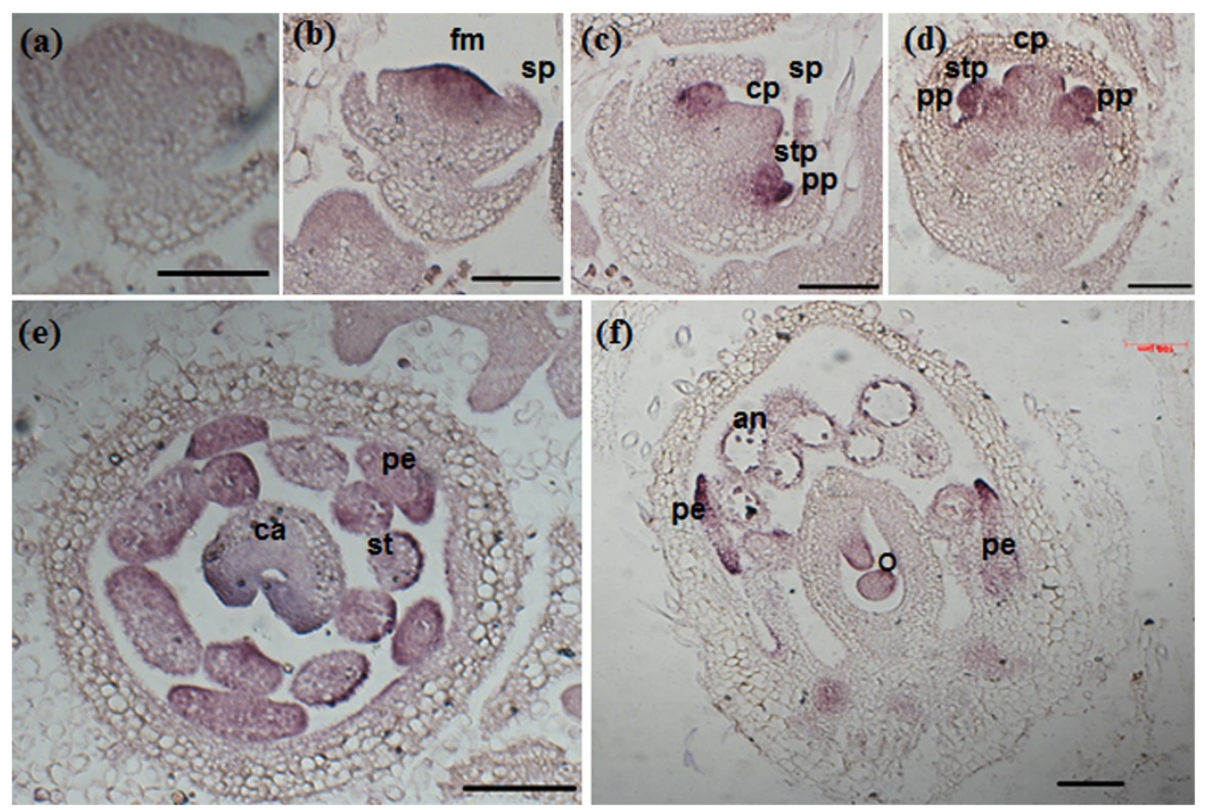

Figure 3 In situ hybridization of GmMADS28 in soybean developing flowers. (a-e) The longitudinal sections of flowers at differential developmental stages hybridized with an antisense (b-f) or sense (a) probe. (e) The cross section of flowers at the mature stage. fm, floral meristem; sp, sepal primordium; pp, petal primordium; stp, stamen primordium; cp, carpel primordium; st, stamen; pe, petal; ca, carpel; an, anther; o, ovule. Bars: $100 \mu \mathrm{m}$.

outer epidermal cells of the tobacco sepal, which are characterized by the presence of globular-tipped trichomes, stomata, and irregularly shaped cells, were used for scanning electron microscopy (SEM) analysis (Figure 6d, g). However, similar to the wild-type carpel, the inner and outer epidermal cells in the 35S:GmMADS28 sepals were regular rectangular-shaped cells (Figure 6e-f, h-i). These results suggest that GmMADS28 might involve in the carpel identity.

\section{S:GmMADS28 plants are sterile due to physical alterations in floral structure}

The 35S:GmMADS28 plants were sterile. To investigate the factors causing sterility, we examined the morphological structure of the floral organs. As shown in Figure 7, eleven 35S:GmMADS28 lines showed shortened and curly filaments, with the filament being shorter than the pistil (Figure 7c, d). The lengths of the filaments were measured before and after stretching. The filament length of 35S: GmMADS28 was significantly shorter than that of wildtype (Figure 7e), and the stamens could not reach the stigma due to such a shortened filament. The SEM analysis on the outer epidermal cells of the filaments was performed to analyze the reason for the shortened filaments. Compared to the wild-type filaments, which contain normal cells (Figure 7f), the 35S:GmMADS28 filaments only have cellular wrinkles, which may lead to curly filaments (Figure 7g).
In addition to shorter filaments, most of the 35S: GmMADS28 anthers cannot split normally, and the pollens cannot be released (Figure 8a-b). To reveal the formation of the unopened anthers, the anthers from 35S: GmMADS28 and wild-type plants were collected at four flower development stages, and the anther morphology of paraffin sections was compared using a microscope. It was found that there were no significant differences between 35S:GmMADS28 and wild-type at the beginning stages of anther maturation (Figure 8c, stages 1 to 2). However, although pollenss were released with the maturation of the wild type (WT) anthers (Figure 8c, stages 3 to 4), the 35S: GmMADS28 anthers could not split (Figure 8c, stages 3 to 4 ) and the pollens were not released.

\section{GmMADS28 activates the expression of SOC1, LEAFY, AGL8/FUL and DEF}

Based on the function of GmMADS28 revealed by its constitutive expression, we studied the expression of 9 genes involved in flowering time or organ identity in the 35S: GmMADS28 leaves. It was observed that the tobacco homologs of the flowering time genes SOC1 and LEAFY, A gene $A G L 8 / F U L$, and B gene $D E F$ were more accumulated in 35S:GmMADS28 compared to wild-type leaves (Figure 9), suggesting that GmMADS28 might directly regulate the expression of these genes, thereby controlling flowering time and petal identity. 


\section{(a)}

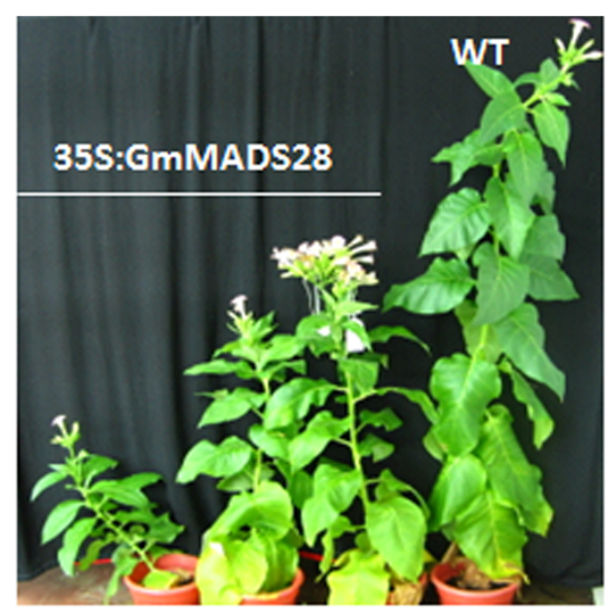

(b)

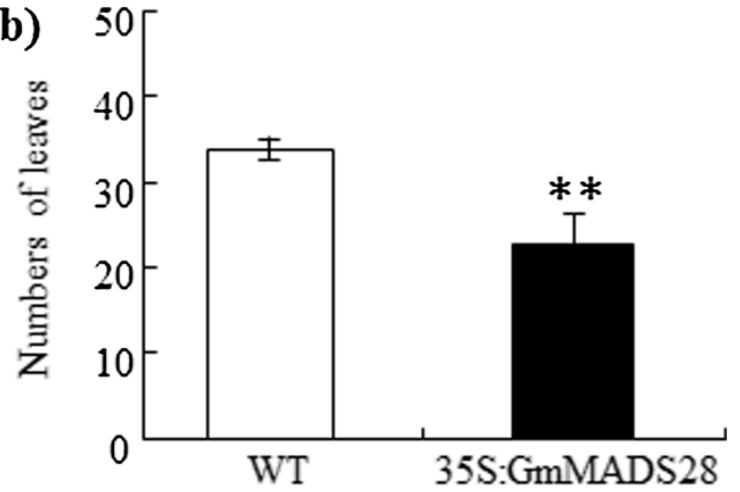

(c)

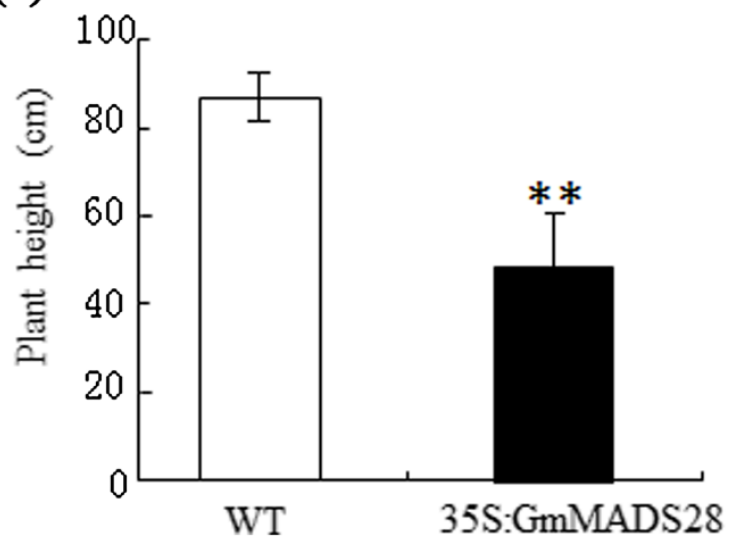

Figure 4 Ectopic expression of GmMADS28 promotes early flowering. (a) Selected transgenic plants at flowering stage. (b) The number of leaves of wild-type and 355:GmMADS28 plants when flowering. (c) The plant height of wild-type and 35S:GmMADS28 plants when flowering. The error bars represent SD $(n=10)$.

GmMADS28 is involved in the conversion of stamens to petals in a soybean mutant

The 35S:GmMADS28 transgenic tobacco plants exhibited the conversion of stamens to petals, which is also the phenotype of soybean mutant NJS-10Hfs [30,33] (Figure 10a). Compared to wild-type soybean stamens, the top areas of most stamens are converted to petallike structure in NJS-10Hfs. Therefore, it is of interest to investigate the expression of GmMADS28 in the flower organs of this mutant. We found that expression of GmMADS28 in the stamens and petals in NJS-10Hfs was higher than in wild-type NJS-10Hff (Figure 10b, c). The expression of GmMADS28 was particularly higher in the mutant stamens ( $\sim 50$ folds) compared to wildtype (Figure 10c), suggesting that the up-regulation of GmMADS28 may play a critical role in the conversion of stamens to petals in this soybean mutant.

\section{GmMADS28 interacts with soybean homologs of SOC1,} AP1, and AGL8/FUL

As MADS-box proteins can form different complexes with different functions during floral development, we screened for interacting partners of GmMADS28 by yeast two hybrid assay using a cDNA library prepared from soybean flowers. A total of five proteins (GmSIP1 GmSIP5), including soybean homologs of AGL8/FUL, SOC1, and AP1 proteins, an ENTH/VHS family protein [34], and an unknown protein, were shown to interact with GmMADS28 (Table 1, Additional file 3: Figure S3). These proteins may form complexes with GmMADS28 and function in the regulation of flowering time and floral development.

\section{Discussion}

Despite their similar sequences, plant SEP3 genes vary in their expression patterns. SEP3 is expressed throughout flower development, from the floral meristem to the fully developed floral organs [35]. The SEP3 genes are expressed in the inner three floral whorls of all species, with the exception of Aranda AdOM1, which is not expressed in stamens and carpels [36]. GmMADS28 also showed a weak expression in the soybean shoot apices in addition to flowers and seeds, indicating that GmMADS28 might also participate in biological events in the shoot apices. In fact, Gerbera GhGRCD2 is also expressed in vegetative tissues [11]. Although GmMADS28 was expressed in all the reproductive organs analyzed, including the four whorl organs, it showed the highest expression level in petals, suggesting that GmMADS28 might play an important role in general flower development but is particularly involved in controlling the identity and development of soybean petals.

To further explore the GmMADS28 function, we ectopically expressed the GmMADS28 gene in tobacco and found that GmMADS28 promotes early flowering. Many studies have shown that the overexpression of SEP3-like gene leads to early flowering $[23,25,37,38]$. In Arabidopsis, the SEP3 protein is potentially incorporated into complexes with proteins involved in flowering time, such as SOC1, AGL24, SVP, and AGL15 [16]. The Arabidopsis 

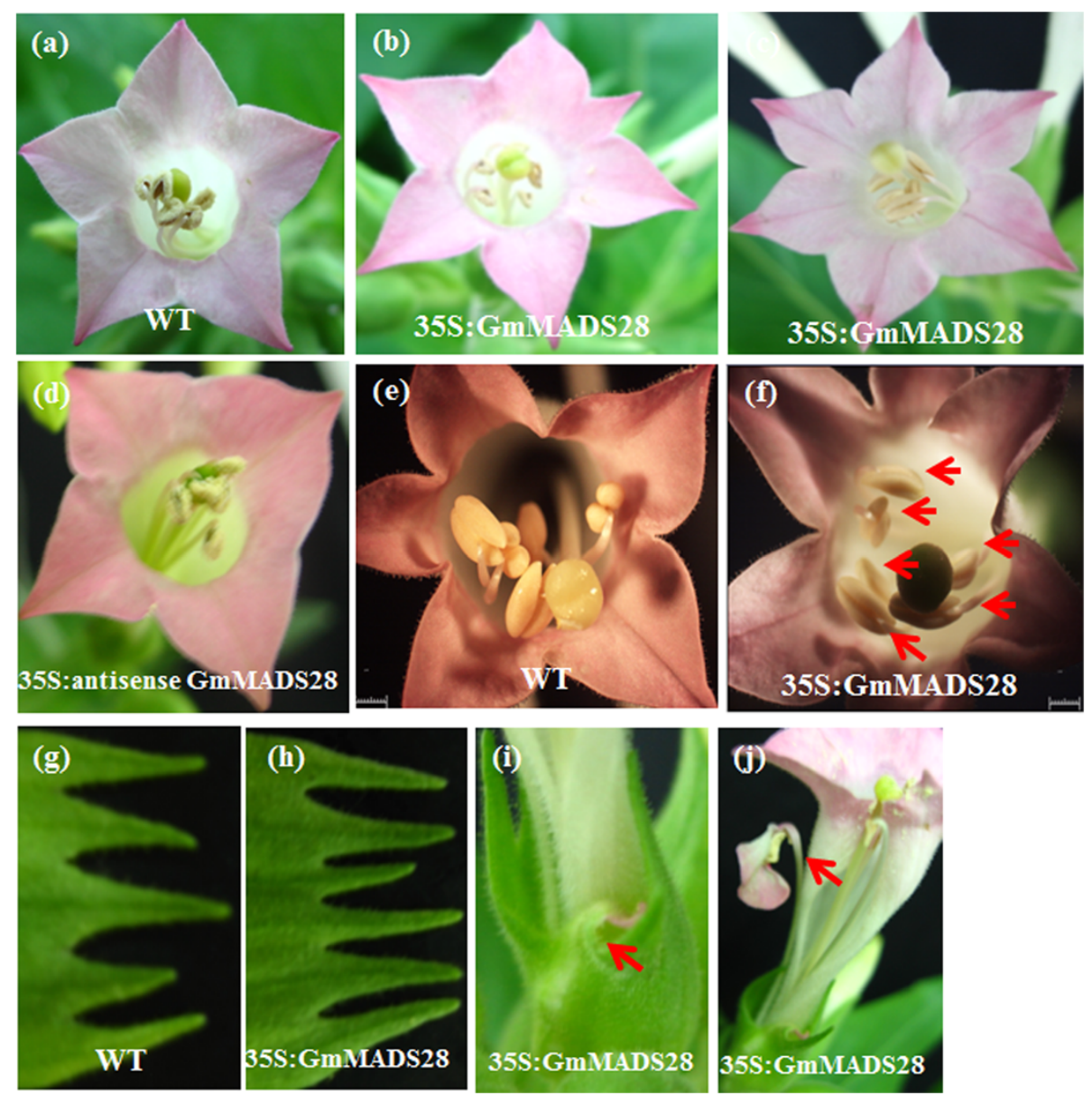

Figure 5 Phenotypes of 35S:GmMADS28 at the reproductive stage. (a, e) WT flower with five petals and stamens. (b, c, f) $355: G m M A D S 28$ flowers with six petals and stamens. (d) 35S:antisense GmMADS28 flower with four petals. (g) WT with five sepals. (h) 35S:GmMADS28 with six sepals. (i) 35S:GmMADS28 converts sepal to petal. (j) 35S:GmMADS28 converts stamen to petal. The arrows in (f) indicate the stamens. Bars: $1 \mathrm{~mm}$ in (e-f).

SOC1-like genes AGL42, AGL71, and AGL72 promote flowering in the shoot apical and axillary meristems [39]. Interestingly, our data showed that GmMADS28 activates the expression of the tobacco homologs of $L E A F Y$ and SOC1, implying that the activated expression of these two genes may lead to early flowering. However, SOC1 was shown to be directly down-regulated by SEP3 in Arabidopsis [18]. These contrasting observations may be due to the different plant systems. Enhanced early flowering was also observed in Arabidopsis plants overexpressing both SEP3 and AP1 genes compared to plants over-expressing AP1 alone [22]. Similarly, we observed that the ectopically expression of soybean GmAP1 also promotes early flowering in Arabidopsis [27]. These results suggest that GmMADS28 and AP1 may be incorporated into the MADS-box protein complex to cooperatively regulate flowering time, which is also supported by the interaction of the GmMADS28 and AP1 proteins by yeast two-hybrid assay.

In Arabidopsis, SEP genes are involved in the development of all four-whorl floral organs and that constitutive expression of SEP3 promotes the homeotic transformation of sepals and inflorescence meristems into carpelloid structures, including ovules [23]. In the present study, a number of floral developmental alterations were observed in GmMADS28 transgenic plants. Interestingly, not all transgenic plants showed the same/similar phenotypes, which is likely because that GmMADS28 as an E-type gene plays a wide role in all most aspects of floral development and different expression level and genome insertion location may influence the phenotypes. Even in one plant, not all the flowers showed the same phenotypes. For example, in the lines with increased number of floral organs, about half of 

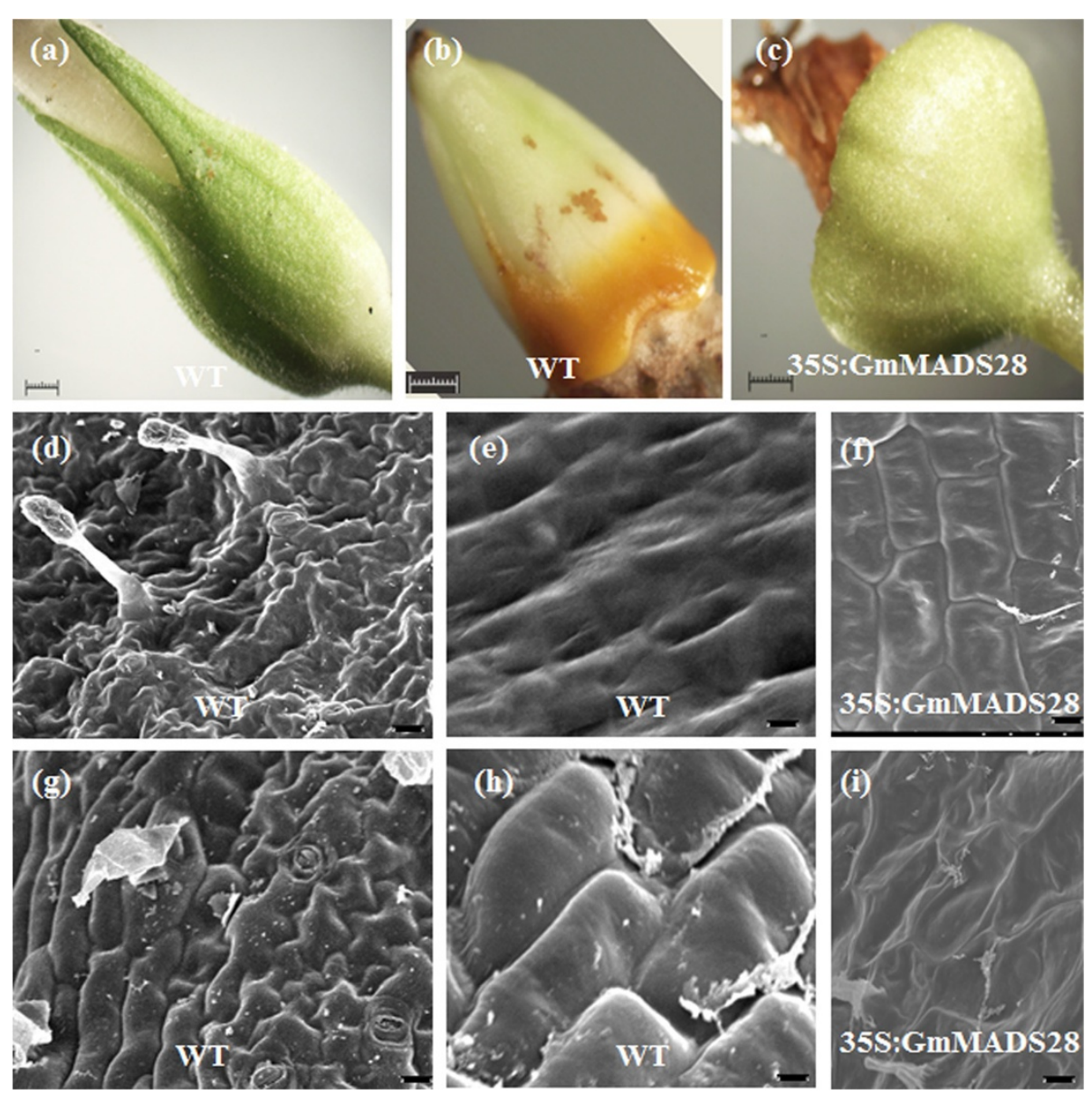

Figure 6 35S:GmMADS28 develops the carpel-like sepals. (a) WT sepal. (b) WT carpel. (c) 35S:GmMADS28 sepal. The inner (d, e, f) and outer $(\mathbf{g}, \mathbf{h}, \mathbf{i})$ epidermal cells of WT sepals and carpels and 35S:GmMADS28 carpel-like sepals were observed through scanning electron microscopy (SEM) analysis. Bars: (a-c) 1 mm; (d, f, g, i) $10 \mu \mathrm{m}$; (e) $5 \mu \mathrm{m}$; (h) $2 \mu \mathrm{m}$.

the flowers altered organ number, while in the sterile lines, all the flowers are sterile.

Ectopic expression of GmMADS28 promoted the development of extra set of floral organs in transgenic tobacco, implying the critical and positive role of GmMADS28 in the formation of floral organs. Interestingly, the antisense expression of GmMADS28 decreased the petal number from five to four, which might have resulted from the decrease of native SEP3 expression in the tobacco flowers. In contrast, Zhao et al. [24] found that the ectopic expression of a wheat SEP-like gene, TaMADS1, decreased the petal and stamen number, suggesting that different SEP proteins might play diverse roles in the regulation of floral development. Our data suggest that GmMADS28 is involved in the formation of four-whorl organs and is particularly required for normal petal and stamen development. The A, $\mathrm{B}, \mathrm{C}$, and SEP proteins likely act as multimeric complexes to activate downstream genes $[8,10,22,40]$. The expression analysis of several ABC genes in 35:GmMADS28 leaves suggests that the ectopic expression of GmMADS28 itself could activate the expression of the DEF and AGL8/FUL genes. The multimeric complexes formed with activated ABC proteins and GmMADS28 may promote the production of extra organs in the transgenic plants.

The ectopic expression of GmMADS28 mediated the conversion of stamens and sepals into petals in transgenic tobacco. In our previous study, we identified a soybean mutant [33] with a phenotype similar to 35S:GmMADS28, with the conversation of stamens into petals. Interestingly, the expression of GmMADS28 in the stamens of the soybean mutant was significantly increased compared to the wild-type plants, and the mRNA in situ localization analysis proved the predominant expression of GmMADS28 in the petal meristem of soybean. These results indicate that GmMADS28 plays a critical and positive role on the $\mathrm{B}$ function. Our data showed that ectopic expression of GmMADS28 activates the expression of B gene DEF [41] in tobacco leaves, suggesting that the ectopic expression 

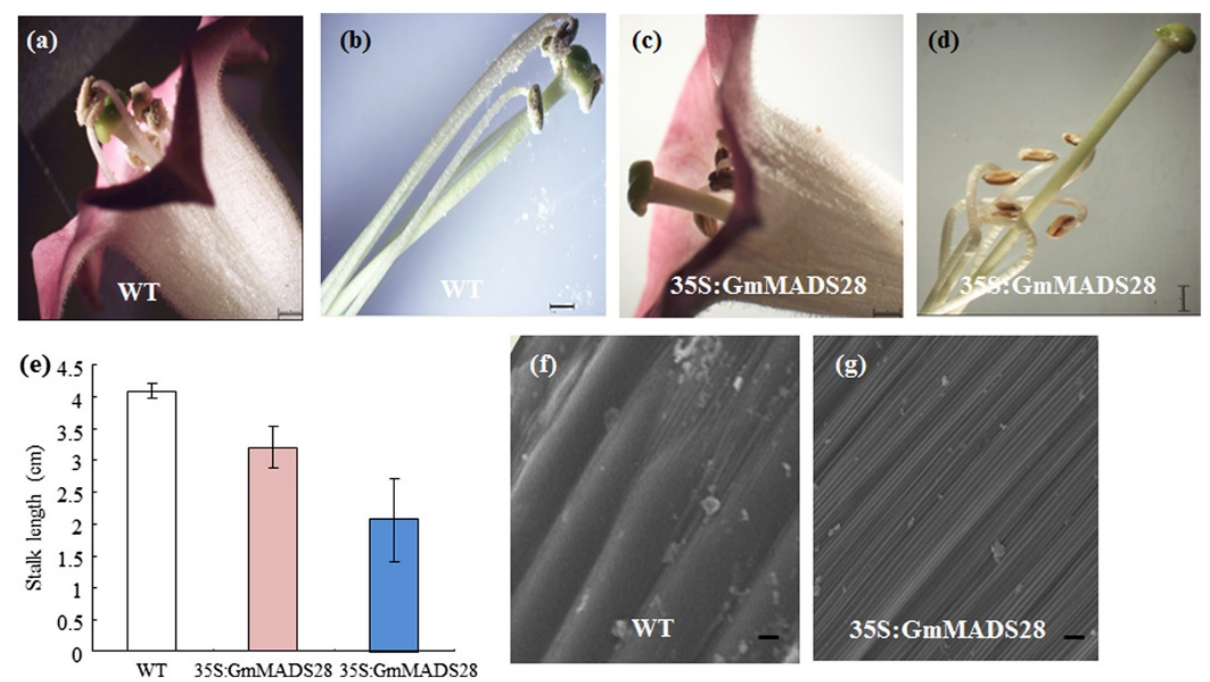

Figure 7 35s:GmMADS28 develops the shortened and curly filaments. (a, b) WT stamens can touch the stigma. (c, d) 35S:GmMADS28 stamens are shortened and curly and cannot touch the stigma. (e) Comparison of filament length of WT and 35S:GmMADS28. The blue column indicates the length of 35S:GmMADS28 curly filaments while the red column the straightened filaments. The error bars represent SD $(n=25)$. (f, g) The epidermal cells of WT and 35S:GmMADS28 filaments were analyzed by SEM. Bars: (a-d) 1 mm, (f) $3 \mu \mathrm{m}$ and (g) $5 \mu \mathrm{m}$.

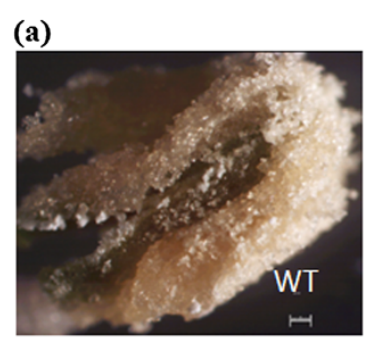

(c)

(b)

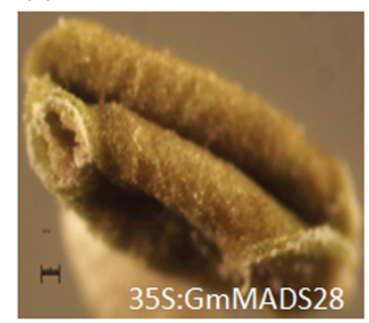

Stage

1
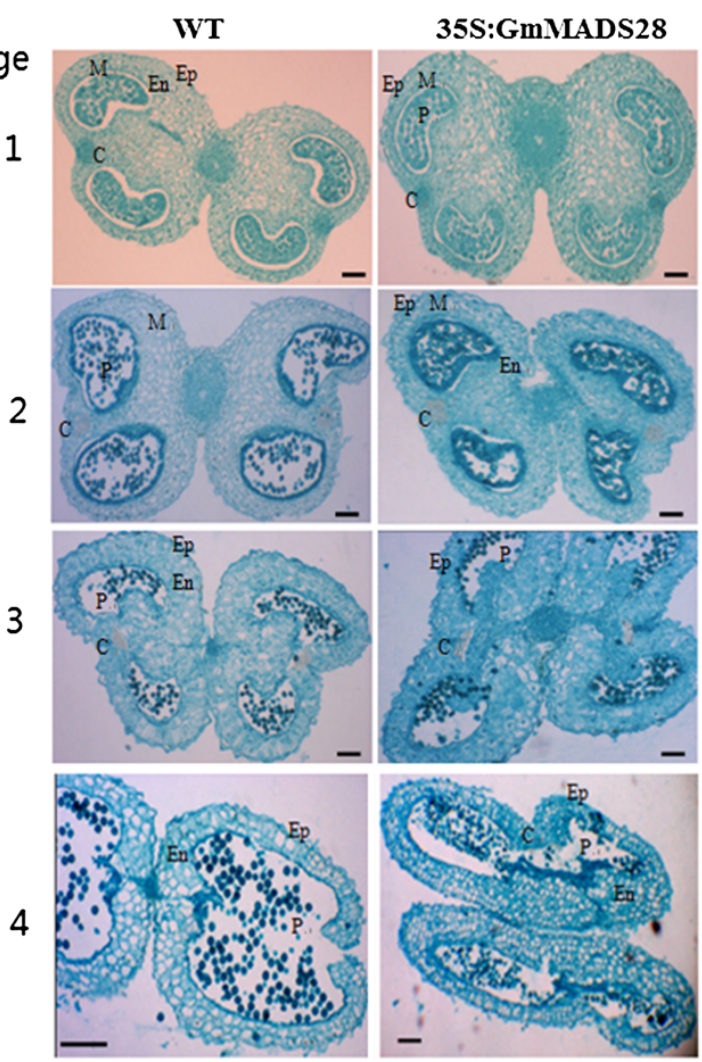

Figure 8 35S:GmMADS28 fails to release the pollens. (a) WT anthers with pollens. (b) 35S:GmMADS28 anthers without pollens covering. (c) Cellular comparison of anther development between WT and 35S:GmMADS28. The anther dehiscence was observed at stage 4 of WT anthers (indicated by red arrow). Ep, epidermic cell; M, middle layer cells; En, endothecium cells; P, pollens; C, parenchyma cells. Bars: (a-c) 100 m. 


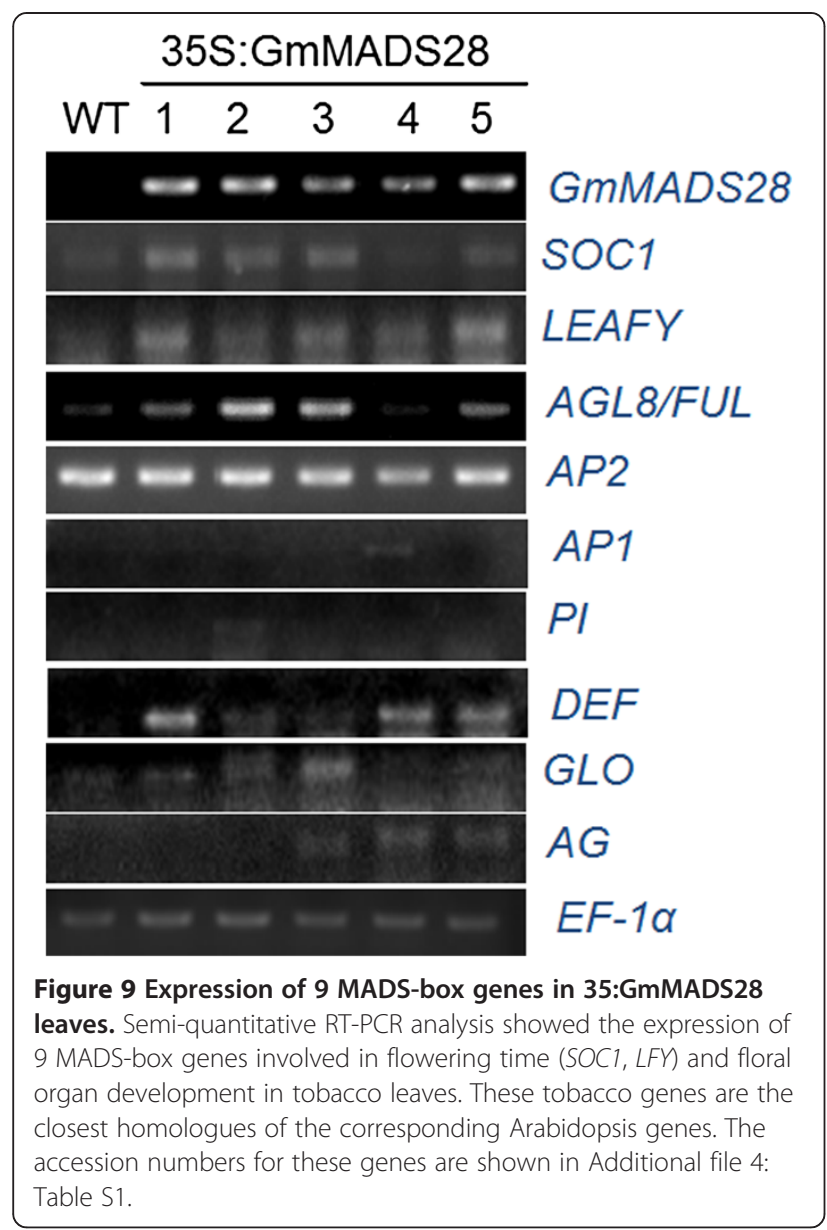

of GmMADS28 can confer B function. Moreover, an A class gene, AGL8/FUL, was activated by GmMADS28. Recently, it was found that FUL-like genes also control flowering time and petal identity in opium poppy [42].

Carpel-like sepals were observed in some of the 35S: GmMADS28 plants and the constitutive expression of SEP3 resulted in the homeotic transformation of sepals and inflorescence meristems into carpelloid structures in Arabidopsis [23]. It has been described that both SEP3 and AG are required for functional $C$ activity $[10,40]$ and that SEP3 could ectopically activate $A G$ [23] in 35S:SEP3 leaves. However, unlike Arabidopsis, the expression of $A G$ was not significantly regulated by GmMADS28 in our study, suggesting that GmMADS28 might have an AGindependent role in the formation of carpel-like sepals.

Controlling male fertility is an important goal for breeding hybrid crops, and male sterility is associated with the failure of pollination in addition to the lack of viable pollen or pollen activity. We observed that the 35S:GmMADS28 plants are sterile, which was caused by two major factors, shortened and curly filaments and the failure of pollen release, which are new findings of SEP3 function. At the beginning stages of anther maturation, (a)

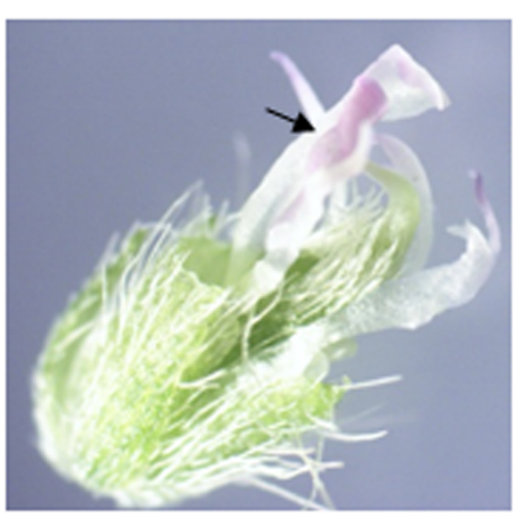

(b)

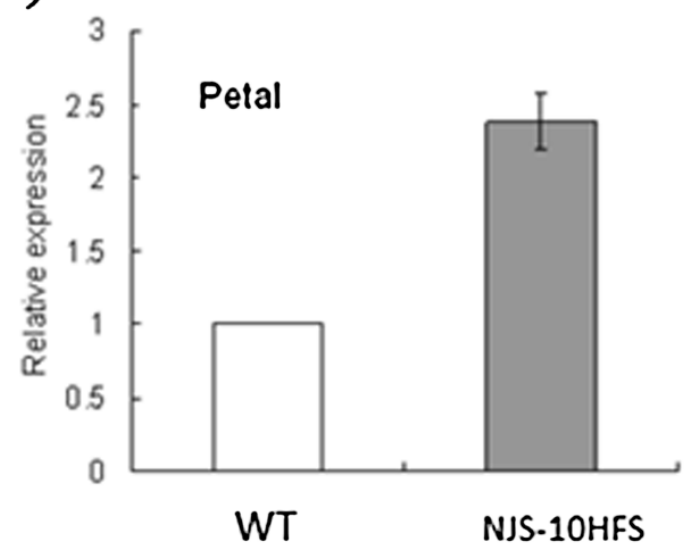

(c)

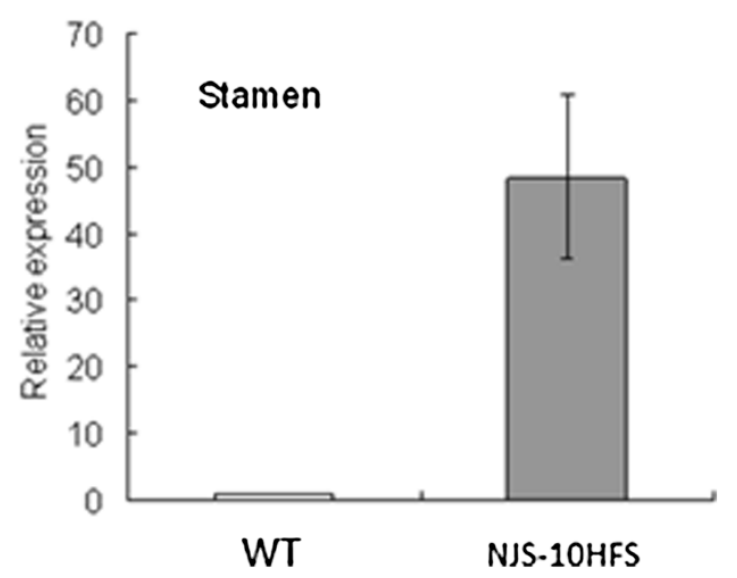

Figure 10 Expression of GmMADS28 in soybean mutant NJS-10Hfs. (a) The flower without petals of the mutant. The arrow indicates the conversion of the stamens into petals. (b) Real-time qPCR analysis of GmMADS28 expression in petals of the mutant NJS-10Hfs and those of WT. (c) Real-time qPCR analysis of GMMADS28 expression in stamens of the mutant NJS-10Hfs and those of WT. The error bars represent SD based on three replicates.

there were no significant differences between 35S: GmMADS28 and the wild type plants. The epidermal cells absorb water from the endothecium cells due to 
Table 1 Soybean proteins interacting with GmMADS28

\begin{tabular}{lll}
\hline Name & Gene ID & Annotation \\
\hline GmSIP1 & Glyma11g36110 & ENTH/NHS family protein \\
GmSIP2 & Glyma05g32820 & Unknown protein \\
GmSIP3 & Glyma04g31800 & AGL8/FUL \\
GmSIP4 & Glyma18g45780 & SOC1 \\
GmSIP5 & Glyma16g13070 & APETALA1 \\
\hline
\end{tabular}

transpiration during anther maturation, which may produce tension in the un-thickened, adjacent regions of the two pollen sacs. For normal anthers, further water loss during maturation causes the parenchyma tissue between the pollen sacs to rupture easily under the tension developed by the endothecium, thus releasing the pollen. For 35S:GmMADS28 anthers, it is hypothesized that the endothecium cells are thickened and the shriveled connection of the cellulose can't pull out the easy-rupture region, the tension was not sufficient to split the anthers; therefore, the pollen grains can't be released.

Unlike the role of GmMADS28, the overexpression of the SEP3 genes from Arabidopsis, tobacco, and rice in wild-type Arabidopsis or tobacco promotes early flowering but does not significantly affect floral morphology $[22,25,26]$. These results suggest that plant SEP3 proteins have common functions in the regulation of flowering time. In this study, we observed the roles of SEP3 proteins in the regulation of floral organ number and petal identity. More importantly, the sterility caused by the ectopic expression of GmMADS28 offers a promising way to genetically produce new sterile material that could potentially be applied in the hybrid breeding of crops like soybean.

\section{Conclusion}

The molecular regulations on reproductive development in soybean are largely unknown. Additionally, controlling the fertility is an important goal in plant hybrid breeding but is difficult in some crops including soybean. Through microarray analysis, a flower-enriched gene GmMADS28 encoding a MADS-box transcription factor was cloned from soybean. GmMADS28 belongs to E-type gene and may play a wide role in reproductive development. It was observed that constitutive expression of GmMADS28 in tobacco caused a number of reproductive development changes, including early flowering, conversion of stamens and sepals to petals, increased numbers of sepal, petal and stamens and carpel-like sepals. In particular, ectopic expression of GmMADS28 caused sterility due to the shortened and curly stalks and the failure of pollen release from the anthers. GmMADS28 is thus a potential target gene for engineering the male sterile plants. Moreover, GmMADS28 was found to activate the tobacco homologs of SOC1, LEAFY, AGL8/FUL and DEF and interact with soybean homologs of SOC1, AP1 and AGL8/FUL proteins, which provides the new clues in understanding the functional mechanisms for E-type proteins in plant reproductive development.

\section{Methods \\ Plant materials}

The soybean (Glycine max L. Merr. cv Jackson) seeds used in this study were obtained from National Center for Soybean Improvement, Nanjing Agricultural University, China, and germinated in the experimental field of Nanjing Agricultural University. Mature leaves (fully expanded), roots, flowers (including flower buds and mature flowers), and pods at 20 days after flowering (DAF) were collected for the real-time RT-PCR analysis. Mature leaves (fully expanded), roots, stems (including internodes and nodes), and shoot apices were collected separately at the stage of the sixth expanding true leaf for semi-quantitative RT-PCR. At the flowering stage, mixed flowers (including flower buds and mature flowers), sepals, petals, stamens, and carpels were collected. Seeds were collected at 15, 20, $25,35,40,45$, and 50 days after flowering.

\section{Cloning of GmMADS28}

To amplify a fragment (Probe ID: Gma.17031.1.A1_at) of GmMADS28, we first obtained the expressed sequence tag (EST) sequence for Gma.17031.1.A1_at by searching the Affymetrix website (https://www.affymetrix. $\mathrm{com} /$ ) using the NetAffx tool. A pair of primers (forward, 5'-GAGATGGGAAGGGGAAGAGT-3; reverse, 5' -ACAAATTGGATATCATCCTG-3') was synthesized for RT-PCR and used with flower cDNA as the template. The PCR conditions were as follows: $0.5 \mu$ flower cDNA was amplified in a $25 \mu \mathrm{l}$ volume containing $2.5 \mu \mathrm{l}$ PCR buffer with $\mathrm{MgCl}_{2}, 0.5 \mu \mathrm{l} 20 \mathrm{mM}$ dNTPs, $1 \mu \mathrm{l}$ Tag polymerase, and $0.5 \mu \mathrm{l}$ each specific primer $(25 \mathrm{mM})$. The PCR amplification was performed using a DNA amplification machine (MJ, USA) with an initial denaturation at $94^{\circ}$ $\mathrm{C}$ for $5 \mathrm{~min}, 33 \mathrm{cycles}$ of $94^{\circ} \mathrm{C}$ for $30 \mathrm{~s}, 55^{\circ} \mathrm{C}$ for $50 \mathrm{~s}$, and $72^{\circ} \mathrm{C}$ for $1 \mathrm{~min}$, and a final $72^{\circ} \mathrm{C}$ for $10 \mathrm{~min}$. The PCR products were gel-purified, cloned into the pGEM-T vector (Promega, USA), and sequenced (Invitrogen, Shanghai, China). Rapid amplification of cDNAs (RACE) was employed with SMART RACE technology (Clontech, USA) to obtain the full-length cDNA for GmMADS28. To amplify the full-length cDNA of GmMADS28, the following pair of primers was used for RT-PCR: forward, 5'-GAGATGGGAAGGGGAAGAGT-3', and reverse, 5' -CAAGGAAGAGGCTAGCTAGG-3'.

\section{Real-time RT-PCR}

Real-time qPCR was performed in an optical 96-well plate using a BIO-RAD iQ5 real-time PCR system (BIO-RAD, USA), as previously described [30]. The soybean Actin 
gene (GenBank accession No. V00450) served as a reference gene. The threshold cycle $(\mathrm{Ct})$ values of the triplicate PCRs were averaged, and the relative quantification of the transcript levels was performed using the comparative $\mathrm{Ct}$ method. To verify the microarray data for GmMADS 28 expression, the relative quantification relates the PCR signal of the target transcript in the roots, flower mixtures, or pods to that in the leaves. The fold change was determined by the following formula: fold change $=2^{-\Delta \Delta \mathrm{Ct}}$, where $\Delta \Delta \mathrm{Ct}=\left(\mathrm{Ct}_{\text {target gene }}-\mathrm{Ct}_{\text {Actin }}\right)_{\text {flowers, roots, or pods }}-$ $\left(\mathrm{Ct}_{\text {target gene }}-\mathrm{Ct}_{\text {Actin }}\right)_{\text {leaves. }}$. For the analysis of GmMADS28 expression in the soybean mutant, the relative quantification relates the PCR signal of the target transcript in the organs of the mutant to that of the wild-type plant. The fold change was determined by the following formula: fold change $=2^{-\Delta \Delta C t}$, where $\Delta \Delta C t=\left(\mathrm{Ct}_{\text {target gene }}-\mathrm{Ct}_{\text {Actin }}\right)$ mutant $-\left(\mathrm{Ct}_{\text {target gene }}-\mathrm{Ct}_{\text {Actin }}\right)_{\text {wild }- \text { type plant }}$.

\section{Semi-quantitative RT-PCR}

Semi-quantitative RT-PCR was performed as previously described [30]. As a control, a 683 bp PCR fragment of the constitutively expressed soybean Actin gene was amplified. The primers for GmMADS28 were as follows: sense, 5'-GAGATGGGAAGGGGAAGAGT-3', and reverse, 5'-CAAGGAAGAGGCTAGCTAGG-3'. For the RT-PCR analysis of nine tobacco MADS-box genes, total RNA was prepared from the leaves of the wild type and five 35S:GmMADS28 plants. The tobacco $E F-1 \alpha$ gene was used as an internal control. The primers for each tobacco MADS-box gene are shown in Additional file 4: Table S1.

\section{RNA in situ hybridization}

Longitudinal and cross sections of soybean flowers were prepared as previously described [27,43]. RNA antisense and sense probes were generated from a $281 \mathrm{bp}$ fragment of the 3' region of the GmMADS28 cDNA labeled with digoxigenin. The RNA in situ hybridization was performed as previously described [27].

\section{Subcellular localization}

To produce the GmMADS28-GFP construct, GmMADS28 was fused in-frame to the $5^{\prime}$ terminus of the green fluorescent protein (GFP) reporter gene under the control of the CaMV35S promoter. The following primers was used for the GmMADS28-GFP construction: 5'-GAGATGG GAAGGGGAAGAGT-3' (forward), and 5'-CAAGGAA GAGGCTAGCTAGG-3' (reverse). The construct was then used in Agrobacterium-mediated transient expression in onion epidermal cells. The cells were examined by confocal laser-scanning microscopy (Leica TCS SP2, Mannheim, Germany).

\section{Ectopic expression in tobacco}

To address the function of GmMADS28, the sense and antisense GmMADS28 sequence were cloned into the plant binary vector pBI121. The recombinant plasmids were used for tobacco (Nicotianatabacum cv. SamSun) transformation via the leaf disk transformation method [44].

\section{Cell morphological analysis}

Tobacco anthers were collected at flower lengths of 0.2 , $0.5,1$, and $3 \mathrm{~cm}$, fixed with Carnoy's Fluid (ethanol: glacial acetic acid $=3: 1$ ) for up to 24 hours at room temperature, and then preserved in $70 \%$ ethanol at $4^{\circ} \mathrm{C}$. After embedding in paraffin, the blocks were trimmed as necessary and cut into $8-10 \mu \mathrm{m}$ sections using a LEICA RM2135 microtome. These sections were stained with safranin and stained again with fast green. After mounting the sections onto slides, the tissues were observed and photographed with a microscope (Leica DMLB).

\section{Yeast two-hybrid assay}

As the full-length GmMADS28 protein has transcriptional activation ability (data not shown), the cDNA sequence encoding GmMADS28 $\triangle \mathrm{C}$ lacking the activation domain (185-243) was used to construct the GAL4-BD fusion pDEST32-GmMADS28 $\triangle C$ as the bait plasmid and used to screen a yeast cDNA library prepared from soybean flowers. The positive clones were then verified by retransformation and subjected to $\beta$-galactosidase assay.

\section{Availability of supporting data}

The sequence of GmMADS28 has been deposited in GenBank/EMBL under accession number AJ878424. The GenBank/EMBL accession numbers of MADS-box proteins used in the phylogenetic tree are: GRCD1 (AJ400623), GRCD2 (AJ784156), SEP1/AGL2 (M55551), SEP4/AGL3 (P29383), SEP2/AGL4 (M55552), SEP3/AGL9 (AF015552), GmSEP1 (DQ159905), OsMADS1 (L34271), OsMADS5 (U78890), ZMM6 (AJ430692), ZMM27 (AJ43 0694), VvMADS4 (AF373603), SISEP3 (BAD10945), LjSEP3 (AY770397).

\section{Additional files}

Additional file 1: Figure S1. GMMADS28 expression during seed development. Actin gene was used as the reference gene. DAF: days after flowering.

Additional file 2: Figure S2. The RT-PCR analysis of 35S:GmMADS28 transgenic plants. P: Positive control, plasmid DNA; WT: wild type plant; 1-13: the 35S:GmMADS28 lines.

Additional file 3: Figure S3. The yeast two hybrid assay identified five proteins (GmSIP1 GmSIP5) interacting with GmMADS28. The cDNA sequence coding GmMADS28 $\triangle \mathrm{C}$ lacking the activation domain was cloned in pDEST32 and used as a bait to screen cDNA library prepared from soybean flowers. The transformation of pEXP'M $32 / \mathrm{Krev} 1$ and pEXP' ${ }^{\text {тм}} 22 / R a l G D S-w t$ or $p$ EXP $^{\text {тм} 22 / R a l G D S-m 1 ~ s e r v e d ~ a s ~ s t r o n g ~ p o s i t i v e ~}$ and weak positive controls while the transformations of EXP $^{\text {TM}} 32 / \mathrm{Krev} 1$ 
and $\mathrm{pEXP}{ }^{\mathrm{T}} 22 / \mathrm{Ra}$ GLDS-m2 or pDEST32 and pDEST22 served as negative controls.

Additional file 4: Table S1. The primer sequences used in gene expression analysis.

\section{Abbreviations}

SEP3: SEPALLATA3; TFs: Transcription factors; FBP11: FLORAL BINDING PROTEIN 11; ORF: Open reading frame; GFP: Green fluorescence protein; DAF: Days after flowering; SEM: Scanning electron microscopy; WT: Wild type; Y2H: Yeast two-hybrid assay; EST: Expressed sequence tag; RACE: Rapid amplification of cDNAs; Ct: Threshold cycle.

\section{Competing interests}

The authors declare that they have no competing interests.

\section{Authors' contributions}

FH: Conceptualization of experiments, clone and sequence characterization of GmMADS28, functional analysis of GmMADS28, writing of manuscript; GLX: Yeast two-hybrid assay, the expression analysis of genes involved in flowering time or organ identity in transgenic plants; YJC: tobacco transformation, Cell morphological analysis; $\mathrm{HCL}$ : Subcellular localization, RNA in situ hybridization; QX: Yeast two-hybrid assay; TJZ: supply of the soybean mutant; JYG: supply of the soybean mutant; DYY: conceptualization of experiments; critical revision of manuscript. All authors read and approved the final manuscript.

\section{Acknowledgments}

This work was supported in part by National Basic Research Program of China (973 Program) (2010CB125906), a project from the Ministry of Agriculture of China for Transgenic Research (2011ZX08009-003), National Natural Science Foundation of China (31371644).

Received: 19 November 2013 Accepted: 27 March 2014 Published: 2 April 2014

\section{References}

1. Weigel D, Meyerowitz EM: The ABCs of floral homeotic genes. Cell 1994, 78:203-209.

2. Theissen G, Melzer R: Molecular mechanisms underlying origin and diversification of the angiosperm flower. Ann Bot 2007, 100(3):603-619.

3. Gramzow L, Theissen G: A hitchhiker's guide to the MADS world of plants. Genome Biol 2010, 11(6):214.

4. Masiero S, Colombo L, Grini PE, Schnittger A, Kater MM: The emerging importance of type I MADS box transcription factors for plant reproduction. Plant Cell 2011, 23(3):865-872.

5. Smaczniak C, Immink RG, Angenent GC, Kaufmann K: Developmental and evolutionary diversity of plant MADS-domain factors: insights from recent studies. Development 2012, 139(17):3081-3098.

6. Colombo L, Franken J, Koetje E, van Went J, Dons HJ, Angenent GC, van Tunen AJ: The petunia MADS-box gene FBP11 determines ovule identity. Plant Cell 1995, 7:1859-1868.

7. Ma H, Yanofsky MF, Meyerowitz EM: AGL1-AGLG an Arabidopsis gene family with similarity to floral homeotic and transcription factor genes. Genes 1991, 12(5):484-495.

8. Pelaz S, Ditta GS, Baumann E, Wisman E, Yanofsky MF: B and C floral organ identity functions require SEPALLATA MADS-box genes. Nature 2000, 405:200-203.

9. Theissen G, Becker A, di Rosa A, Kanno A, Kim JT, Munster T, Winter KU, Saedler H: A short history of MADS-box genes in plants. Plant Mol Biol 2000, 42:115-149.

10. Ditta G, Pinyopich A, Robles P, Pelaz S, Yanofsky MF: The SEP4 gene of Arabidopsis thaliana functions in floral organ and meristem identity. Curr Biol 2004, 14:1935-1940.

11. Malcomber ST, Kellogg EA: SEPALLATA gene diversification: brave new whorls. Trends Plant Sci 2005, 10(9):427-435.

12. Theissen G: Development of floral organ identity: stories from the MADS house. Curr Opin Plant Biol 2001, 4:75-85.

13. Krizek BA, Fletcher JC: Molecular mechanisms of flower development: an armchair guide. Nat Rev Genet 2005, 6(9):688-698.

14. Ciaffi M, Paolacci AR, Tanzarella OA, Porceddu E: Molecular aspects of flower development in grasses. Sex Plant Reprod 2011, 24(4):247-282.
15. Uimari A, Kotilainen M, Elomaa P, Yu D, Albert VA, Teeri TH: Integration of reproductive meristem fates by a SEPALLATA-like MADS-box gene. Proc Natl Acad Sci U S A 2004, 101:15817-15822.

16. Immink RG, Kaufmann $\mathrm{K}$, Angenent GC: The 'ABC' of MADS domain protein behaviour and interactions. Semin Cell Dev Biol 2009, 21:87-93.

17. Favaro R, Pinyopich A, Battaglia R, Kooiker M, Borghi L, Ditta G, Yanofsky MF, Kater MM, Colombo L: MADS-box protein complexes control carpel and ovule development in Arabidopsis. Plant Cell 2003, 15:2603-2611.

18. Kaufmann K, Muiño JM, Jauregui R, Airoldi CA, Smaczniak C, Krajewski P, Angenent GC: Target genes of the MADS transcription factor SEPALLATA3: integration of developmental and hormonal pathways in the Arabidopsis flower. PLoS Biol 2009, 7(4):e1000090.

19. Gao X, Liang W, Yin C, Ji S, Wang H, Su X, Guo C, Kong H, Xue H, Zhang D: The SEPALLATA-like gene OSMADS34 is required for rice inflorescence and spikelet development. Plant Physiol 2010, 153(2):728-740.

20. Kobayashi K, Maekawa M, Miyao A, Hirochika H, Kyozuka J: PANICLE PHYTOMER2 (PAP2), encoding a SEPALLATA subfamily MADS-box protein, positively controls spikelet meristem identity in rice. Plant Cell Physiol 2010, 51(1):47-57.

21. Cui R, Han J, Zhao S, Su K, Wu F, Du X, Xu Q, Chong K, Theissen G, Meng Z: Functional conservation and diversification of class $E$ floral homeotic genes in rice (Oryza sativa). Plant J 2010, 61(5):767-781.

22. Pelaz S, Gustafson-Brown C, Kohalmi SE, Crosby WL, Yanofsky MF: APETALA1 and SEPALLATA3 interact to promote flower development. Plant $\lrcorner$ 2001, 26:385-394.

23. Castillejo C, Romera-Branchat M, Pelaz S: A new role of the Arabidopsis SEPALLATA3 gene revealed by its constitutive expression. Plant J 2005, 43(4):586-596.

24. Zhao T, Ni Z, Dai Y, Yao Y, Nie X, Sun Q: Characterization and expression of 42 MADS-box genes in wheat (Triticum aestivum L.). Mol Genet Genomics 2006, 276(4):334-350

25. Kang $H G$, An G: Isolation and characterization of a rice MADS-box gene belonging to the AGL2 gene family. Mol Cells 1997, 7:45-51.

26. Jang S, Hong MY, Chung YY, An G: Ectopic expression of tobacco MADS genes modulates flowering time and plant architecture. Mol Cells 1999, 9:576-586.

27. Chi YJ, Huang F, Liu HC, Yang SP, Yu DY: An APETALA1-like gene of soybean regulates flowering time and specifies floral organs. J Plant Physiol 2011, 168:2251-2259.

28. Wu CX, Ma QB, Yam KM, Cheung MY, Xu YY, Han TF, Lam HM, Chong K: In situ expression of the GmNMH7 gene is photoperiod-dependent in a unique soybean (Glycine max [L.] Merr.) flowering reversion system. Planta 2006, 223:725-735.

29. Zhong X, Dai X, XV J, Wu H, Liu B, Li H: Cloning and expression analysis of GmGAL1, SOC1 homolog gene in soybean. Mol Biol Rep 2012, 39(6):6967-6974.

30. Huang F, Chi YJ, Meng QC, Gai JY, Yu DY: Identification of transcription factors predominantly expressed in soybean flowers and characterization of GMSEP1 encoding a SEPALLATA1-like protein. Gene 2009, 438:40-48.

31. Zahn LM, Kong H, Leebens-Mack JH, Kim S, Soltis PS, Landherr LL, Soltis DE, de Pamphilis CW, Ma H: The evolution of the SEPALLATA subfamily of MADS-box genes: a pre-angiosperm origin with multiple duplications throughout angiosperm history. Genetics 2005, 169:2209-2223.

32. Kanno A, Hienuki H, Ito T, Nakamura T, Fukuda T, Yun PY, Song IJ, Kaminura T, Ochiai T, Yokoyama J, Maki M, Kameya T: The structure and expression of SEPALLATA-like genes in Asparagus specie (Asparagaceae). Sex Plant Rep 2006, 19:133-144.

33. Zhao TJ, Gai JY: A new soybean female sterile mutant with abnormal leaves and flowers. Soy Sci 2005, 24:1-4.

34. De Camilli P, Chen H, Hyman J, Panepucci E, Bateman A, Brunger AT: The ENTH domain. FEBS Lett 2002, 513(1):11-18.

35. Mandel MA, Yanofsky MF: The Arabidopsis AGL9 MADS box gene is expressed in young flower primordia. Sex Plant Reprod 1999, 11:22-28.

36. Lu ZX, Wu M, Loh CS, Yeong CY, Goh CJ: Nucleotide sequence of a flower-specific MADS box CDNA clone from orchid. Plant Mol Biol 1993, 23:901-904

37. Jeon JS, Lee S, Jung KH, Yang WS, Yi GH, Oh BG, An GH: Production of transgenic rice plants showing reduced heading date and plant height by ectopic expression of rice MADS-box genes. Mol Breeding 2000, 6:581-592. 
38. Ferrario S, Immink RG, Shchennikova A, Busscher-Lange J, Angenent GC: The MADS box gene $f b p 2$ is required for sepallata function in petunia. Plant Cell 2003, 15:914-925.

39. Dorca-Fornell C, Gregis V, Grandi V, Coupland G, Colombo L, Kater MM: The Arabidopsis SOC1-like genes AGL42, AGL71 and AGL72 promote flowering in the shoot apical and axillary meristems. Plant J 2011, 67(6):1006-1017.

40. Honma T, Goto K: Complexes of MADS-box proteins are sufficient to convert leaves into floral organs. Nature 2001, 409:525-529.

41. Mouradov A, Hamdorf B, Teasdale RD, Kim JT, Winter KU, Theissen G: A $D E F / G L O-$ like MADS-box gene from a gymnosperm: Pinus radiata contains an ortholog of angiosperm B class floral homeotic genes. Dev Genet 1999, 25:245-252.

42. Pabón-Mora N, Ambrose BA, Litt A: Poppy APETALA1/FRUITFULL orthologs control flowering time, branching, perianth identity, and fruit development. Plant Physiol 2012, 158(4):1685-1704.

43. Coen ES, Romero JM, Doyle S, Elliott R, Murphy G, Carpenter R: Floricaula: a homeotic gene required for flower development in Antirrhinum majus. Cell 1990, 63:1311-1322.

44. Burow MD, Chlan CA, Sen P, Lisca A, Murai N: High-frequency generation of transgenic tobacco plants after modified leaf disk cocultivation with Agrobacterium tumefaciens. Plant Mol Bio Rep 1990, 8:124-139.

doi:10.1186/1471-2229-14-89

Cite this article as: Huang et al: A soybean MADS-box protein modulates floral organ numbers, petal identity and sterility. BMC Plant Biology 2014 14:89.

\section{Submit your next manuscript to BioMed Central and take full advantage of:}

- Convenient online submission

- Thorough peer review

- No space constraints or color figure charges

- Immediate publication on acceptance

- Inclusion in PubMed, CAS, Scopus and Google Scholar

- Research which is freely available for redistribution 